\title{
Mechanism of the Facile Nitrous Oxide fixation by Homogeneous Ruthenium Hydride Pincer Catalysts
}

\author{
Sílvia Escayola, ${ }^{\star}$ Miquel Solà, ${ }^{\ddagger} *$ and Albert Poater ${ }^{\ddagger} *$ \\ IInstitut de Química Computacional i Catàlisi and Departament de Química, Universitat de Girona, C/ Mª Aurèlia Capmany 69, 17003 \\ Girona, Catalonia, Spain
}

\begin{abstract}
Solving ozone depletion and climate change problems require the development of effective methods for sustainably curbing them. With this aim, Milstein and coworkers developed a PNP pincer ruthenium catalyst for the homogeneous hydrogenation of nitrous oxide $\left(\mathrm{N}_{2} \mathrm{O}\right)$, an ozone-depleting substance and the third most important greenhouse gas, to generate dinitrogen and water as resultant products. The mechanism of this promising transformation was unveiled by means of experiments together with Density Functional Theory (DFT) calculations, which inspired Milstein and coworkers to use similar (PNN)Ru-H pincer catalysts for the reduction of $\mathrm{N}_{2} \mathrm{O}$ by $\mathrm{CO}$ to produce $\mathrm{N}_{2}$ and $\mathrm{CO}_{2}$. The use of the latter type of catalysts resulted in the proposition of a new reaction protocol and allowed to work under milder conditions. Here we describe the detailed mechanism of the last transformation catalyzed by a (PNN)Ru-H catalyst by means of DFT calculations, and not only this, but we also discover the way to block undesired parasitic reactions. Apart from that, we have explored a new evolution of this family of catalysts to go beyond previous experimental outcomes. The mechanism consists in a cascade of easy steps, starting from an insertion of the $\mathrm{N}_{2} \mathrm{O}$ oxygen into the $\mathrm{Ru}-\mathrm{H}$ bond generating a hydroxo intermediate and releasing $\mathrm{N}_{2}$, and ending with a $\beta$ hydride elimination to form $\mathrm{CO}_{2}$ and regenerate the catalyst. The whole process occurs in a facile way with the exception of two steps: the formation of the hydroxyl ligand and the final $\beta$-hydride elimination to form $\mathrm{CO}_{2}$. However, the energy barriers of these two steps are not the bottleneck of the catalysis, but rather the easiness of the pyridyl group bonded to $\mathrm{Ru}$ to isomerize by $\mathrm{C}-\mathrm{H}$ activation. We propose to solve this drawback by tuning the PNN ligand to block the pyridyl free rotation.
\end{abstract}

KEYWORDS: ruthenium, metal hydride, catalysis, pincer ligand, green chemistry, $\mathrm{N}_{2} \mathrm{O}$ reduction, $\mathrm{CO}$ fixation

\section{INTRODUCTION}

Over the last fifty years, the concerns about the chemical anthropogenic perturbations to the composition of the atmosphere have become more notorious, especially because of the fatal consequences derived from it. ${ }^{1}$ The efforts to stop and reverse this situation allowed to identity most of the global warming (GW) agents. ${ }^{2}$ The variety of existing greenhouse gases (GHGs) and/or ozone depleting substances (ODSs) is huge, including gases like methane $\left(\mathrm{CH}_{4}\right)$, hydrofluorocarbons (HFCs), sulphur hexafluoride $\left(\mathrm{SF}_{6}\right)$, perfluorocarbons (PFCs), carbon dioxide $\left(\mathrm{CO}_{2}\right)$ or nitrous oxide $\left(\mathrm{N}_{2} \mathrm{O}\right)$. Among them, $\mathrm{CO}_{2}$ and $\mathrm{N}_{2} \mathrm{O}$ are recognized as the main responsible agents with a great $\mathrm{GW}$ potential. ${ }^{3,4}$ By itself, $\mathrm{CO}_{2}$ represents an $80 \%$ of the $\mathrm{GHGs},{ }^{5}$ becoming the major contributor to the $\mathrm{GH}$ effect, nonetheless $\mathrm{N}_{2} \mathrm{O}$ is more harmful since it is not only a GHG but also an ODS. Whereas the traditionally dominant ODSs (chlorofluorocarbons) have been greatly reduced with the adoption of strict protocols, ${ }^{6} \mathrm{~N}_{2} \mathrm{O}$ emissions have been maintained during the last two decades and, consequently, $\mathrm{N}_{2} \mathrm{O}$ has become one of the today's most significant ODSs. Moreover, $\mathrm{N}_{2} \mathrm{O}$ is nearly 300 times more powerful than $\mathrm{CO}_{2}$ at trapping heat in the atmosphere and it is much more persistent than other GHGs such as $\mathrm{CH}_{4}$, due to its steady-state lifetime of about 120 years. ${ }^{7,8}$ The main sources of $\mathrm{N}_{2} \mathrm{O}$ are fertilizers, pesticides, and burning fossil fuels, between them agriculture is the major responsible of its generation representing a $56-81 \%$ of the anthropogenic contribution. ${ }^{9,10}$ Some emissions associated with food production are inevitable, and it is estimated that with a business-as-usual scenario, by 2050 we will double our $\mathrm{N}_{2} \mathrm{O}$ emissions. ${ }^{11}$ For all these reasons, it is crucial to find ways to destruct or functionalize this hazardous gas, decreasing its levels in the atmosphere. Chemically, the cleanest way to eliminate $\mathrm{N}_{2} \mathrm{O}$ is by a reductive process, such as the hydrogenation of $\mathrm{N}_{2} \mathrm{O}$ to generate innocuous $\mathrm{N}_{2}$ and $\mathrm{H}_{2} \mathrm{O}$. This procedure has proved feasible using homogeneous ${ }^{12,13}$ and heterogeneous ${ }^{14}$ catalytic systems. Thus, this sustainable reaction has become of great interest in the field of green chemistry. ${ }^{15,16}$ However, the reaction mechanisms of the reported homogeneous catalysts were poorly characterized, and in some cases the reactions involving $\mathrm{N}_{2} \mathrm{O}$ and those metal complexes proceed under stoichiometric conditions. ${ }^{12}$

Over last years, Milstein and coworkers have been developing new metal complexes, ${ }^{13,17,18}$ bearing PNP and PNN pincer ligands, for the homogeneously catalyzed reduction of $\mathrm{N}_{2} \mathrm{O}$ by $\mathrm{H}_{2}$ and also exploring other possible reactions changing the reducing agent (i.e. using $\mathrm{CO}$ instead of $\mathrm{H}_{2}$ ). The used meridional tridentate chelate ligands are prone to switch on/off the aromaticity, ${ }^{19,20}$ specially when being part of a pyridyl moiety affecting the reaction energetics,${ }^{21}$ as Gonçalves and Huang proved from a computational point of view. ${ }^{22}$

The new protocol for the homogeneously catalyzed $\mathrm{N}_{2} \mathrm{O}$ reduction, with $\mathrm{CO}$ as reducing agent was proposed by Milstein and coworkers in 2018 using a set of ruthenium hydride pincer complexes, holding PNN pincer ligands (see Scheme 1). ${ }^{23,24}$ which displayed higher TONs than PNP ones. 


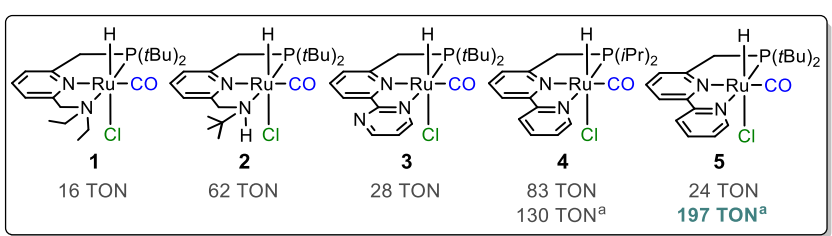

$$
\mathrm{N}_{2} \mathrm{O}+\mathrm{CO} \underset{\text { mild conditions }}{\stackrel{\text { [catalyst] }}{\longrightarrow}} \mathrm{N}_{2}+\mathrm{O}=\mathrm{C}=\mathrm{O}
$$

Scheme 1. Reduction of $\mathrm{N}_{2} \mathrm{O}$ by the PNN-pincer Ru based catalysts 1-5. For the reaction, $0.01 \mathrm{mmol}$ of catalyst, $0.01 \mathrm{mmol}$ of base $(t \mathrm{BuOK}), 3.7 \mathrm{mmol}$ of $\mathrm{CO}$ and $7.4 \mathrm{mmol}$ of $\mathrm{N}_{2} \mathrm{O}$ in $4 \mathrm{ml}$ of toluene were used, at a temperature of $100^{\circ} \mathrm{C}$ during $22 \mathrm{~h}$. ( ${ }^{a}$ the reaction was conducted in THF at $70{ }^{\circ} \mathrm{C}$ ).

In the proposed reaction mechanism, the oxygen of the $\mathrm{N}_{2} \mathrm{O}$ molecule is selectively inserted into the $\mathrm{Ru}-\mathrm{H}$ bond by means of an $\mathrm{O}$-atom transfer (OAT) process (first steps of cycle A in Scheme 2, from intermediate $\mathbf{7}$ to $\mathbf{1 0}$ ). The OAT process was computationally characterized using similar Ru-based complexes, ${ }^{25}$ and it is known to occur in a stepwise manner; starting with a nucleophilic attack of the hydride ligand on the $\mathrm{N}_{2} \mathrm{O}$ terminal $\mathrm{N}$ followed by a concerted $\mathrm{N}_{2}$ release.

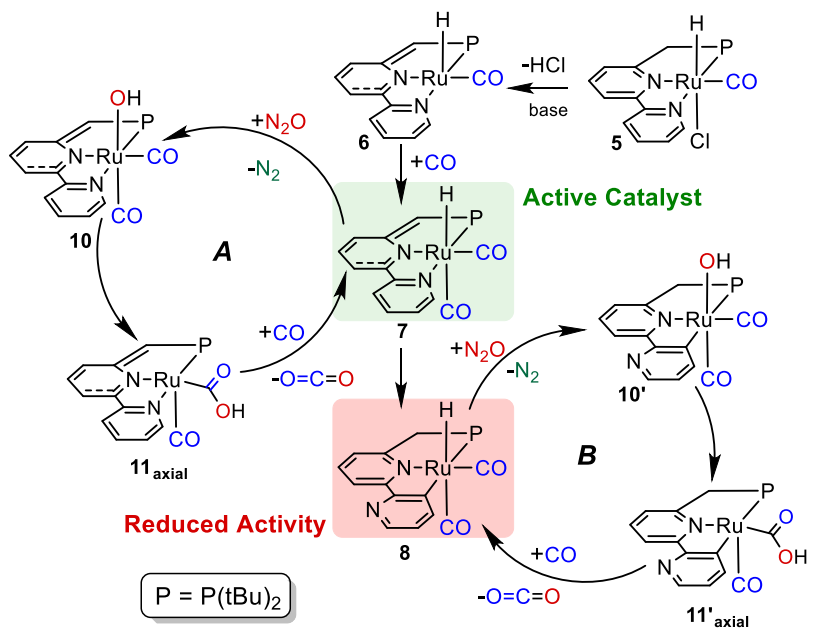

Scheme 2. Proposed mechanism by Milstein and coworkers, with all intermediates characterized by X-Ray crystallography and/or NMR techniques.

After the OAT step, the formed Ru-OH intermediate evolves to a $\mathrm{Ru}-\mathrm{COOH}$ species (intermediate $\mathbf{1 1}_{\text {axial, }}$ with one $\mathrm{CO}$ in axial position), resulting from the intramolecular nucleophilic attack of the $\mathrm{OH}$ moiety on the adjacent $\mathrm{CO}$ ligand. Next a $\beta$-hydride elimination takes place, resulting in the liberation of $\mathrm{CO}_{2}$ and the regeneration of the catalytic species (7) in the presence of $\mathrm{CO}$. However, the exact mechanism is still unknown. Thus, one of our goals is to characterize both the OAT and the $\mathrm{CO}_{2}$ release steps for the particular case of the CO oxidation catalyzed by the (PNN)RuH complex 5 by means of Density Functional Theory (DFT). Our calculations are guided by the many experiments conducted by Milstein and coworkers ${ }^{23}$ who gave detailed mechanistic insight about the catalytic cycle (see Scheme 2).

Even though the (PNN)Ru-H complex presents promising catalytic activity, it is important to remark that over time the active species 7 suffers an isomerization process forming the less active for $\mathrm{N}_{2} \mathrm{O}$ fixation compound $\mathbf{8}$. In compound $\mathbf{8}$, the lateral pyridine of the $\mathrm{PNN}$ ligand is coordinated to the metal through the $\mathrm{C}$ atom (in meta with respect the $\mathrm{N}$ ) instead of $\mathrm{N}$ and the $\mathrm{C}=\mathrm{C}$ double bond of the bridge connecting the phosphine ligand with the pyridine ring is reduced, resulting in the recovery of the aromaticity of the central pyridine moiety. ${ }^{26}$ Consequently, we explored computationally the isomerization reaction and the catalytic cycle $\mathrm{B}$ to understand the decrease of the activity due to the formation of species $\mathbf{8}$. In addition, we proposed and test new complexes with modified PNN ligands specially designed to avoid the transformation from $\mathbf{7}$ to $\mathbf{8}$.

We also tested different Ru-based catalysts for the CO oxidation reaction, including PNP and PNN pincer ligands, to unravel the different activity according to the nature of the pincer ligand. The phosphine substituents and the solvent also influence the activity of the complex, the best candidates for the catalysis being the complexes bearing $\mathrm{PNN}$ ligands with $\mathrm{P}(t \mathrm{Bu})_{2}$ and $\mathrm{P}(i \mathrm{Pr})_{2}$ moieties in a THF solution.

\section{- RESULTS AND DISCUSSION}

Calculations begin from the X-Ray data for complex $\mathbf{5}$. Treatment of this species with a base $(t \mathrm{BuOK})$ generates intermediate 6 . Then, the coordination of a CO ligand is exergonic by $14.5 \mathrm{kcal} / \mathrm{mol}$ and leads to the catalytically active species 7 . The catalytic cycle A in Figure 1 starts with $\mathrm{O}$-atom insertion of the $\mathrm{N}_{2} \mathrm{O}$ into the $\mathrm{Ru}-\mathrm{H}$ bond with an energy barrier of $31.4 \mathrm{kcal} / \mathrm{mol}$. The next step corresponds to the $\mathrm{N}_{2}$ release with a barrier of $22.7 \mathrm{kcal} / \mathrm{mol}(33.5 \mathrm{kcal} / \mathrm{mol}$ from 7) and extremely favored thermodynamics $(62.7 \mathrm{kcal} / \mathrm{mol})$. The kinetics are favored by $6.8 \mathrm{kcal} / \mathrm{mol}$ when assisted by an external water molecule, however without the latter assistance the energy barrier is still reasonable $(29.5 \mathrm{kcal} / \mathrm{mol})$. After the $\mathrm{N}_{2}$ release, intermediate $\mathbf{1 0}$ bearing a hydroxyl ligand is rather reactive and together with the closest carbonyl ligand collapses into a carboxylic ligand trans to the central pyridine ring of the pincer ligand (11 axial) overcoming an energy barrier of $15.2 \mathrm{kcal} / \mathrm{mol}$. 


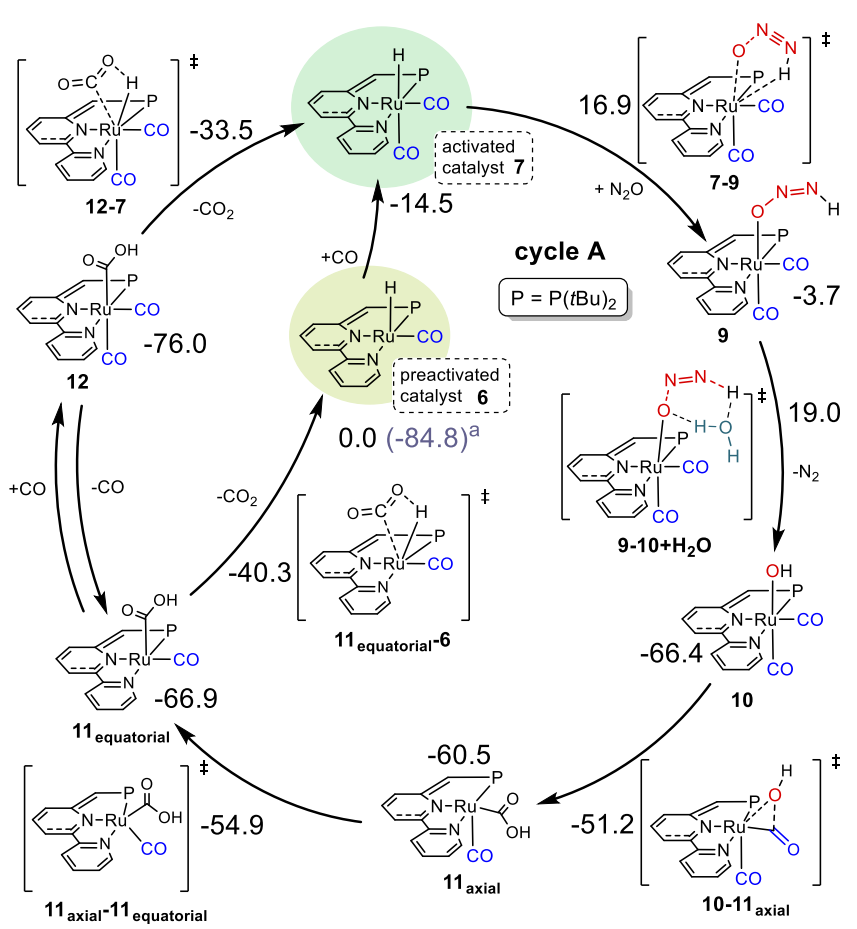

Figure 1. Computed mechanism for the $\mathrm{CO}$ oxidation by $\mathrm{N}_{2} \mathrm{O}$ homogeneously catalyzed by ruthenium hydride pincer $\mathbf{7}$ following cycle A (relative Gibbs energies in solution and referred to catalyst $\left.\mathbf{6}+\mathrm{CO}+\mathrm{N}_{2} \mathrm{O}\right)$. Energies are given in $\mathrm{kcal} / \mathrm{mol}$. All data shown were calculated at $\mathrm{T}=70{ }^{\circ} \mathrm{C}$, mimicking the experiments. See SI Figure $\mathrm{S} 2$ for a more detailed picture. ${ }^{\mathrm{a}}$ Complex $\mathbf{6}+\mathrm{CO}_{2}+\mathrm{N}_{2}$ after one catalytic cycle has a Gibbs energy of $-84.8 \mathrm{kcal} / \mathrm{mol}$, corresponding to the exoergonicity of the $\mathrm{CO}+\mathrm{N}_{2} \mathrm{O} \rightarrow \mathrm{CO}_{2}+\mathrm{N}_{2}$ reaction.

Due to the fact that basal sites of a nearly flat square pyramid are more $\pi$-basic than apical sites, the $\pi$-acidic ligands (i.e. $\mathrm{CO}$ ) will tend to occupy these basal positions to get an extra stabilization given by the stronger backbonding. ${ }^{27}$ Therefore, thermodynamics favors that the new carboxylic ligand flips to cis (11 equatorial), to place again a carbonyl group trans to the central pyridine moiety. This step is rather facile, with a low energy barrier of $5.6 \mathrm{kcal} / \mathrm{mol}$, and releasing $6.4 \mathrm{kcal} / \mathrm{mol}$. At this point, the final $\mathrm{CO}_{2}$ release can follow different mechanisms starting from complex 11 equatorial to regenerate the catalytic species $\mathbf{7}$ overcoming an energy barrier of $35.7\left(\Delta \mathrm{G}^{\ddagger}\right.$ between $\mathbf{1 2}$ and $\mathbf{1 1}$ equatorial-6) or $42.5 \mathrm{kcal} / \mathrm{mol}\left(\Delta \mathrm{G}^{\ddagger}\right.$ between 12 and 12-7). In all cases, the reaction follows a stepwise process involving the coordination of a $\mathrm{CO}$ ligand and a $\beta$-hydride elimination to release $\mathrm{CO}_{2}$. The difference between them is the decoordination of the axial $\mathrm{CO}$ ligand. In the first case, this $\mathrm{CO}$ is decoordinated and then the $\mathrm{CO}_{2}$ is released (via the transition state 11 equatorial-6) forming intermediate $\mathbf{6}$, whereas, in the other case, the CO keeps coordinated to the metal during the elimination step. The first mechanism is the most likely to occur, because the energy barrier for the second mechanism is too high to be reached working at $70{ }^{\circ} \mathrm{C}$. Moreover, even intermediate $\mathbf{1 2}$ is more stable than 11 equatorial by $9.1 \mathrm{kcal} / \mathrm{mol}$, the low concentration of $\mathrm{CO}$ in solution favors the decoordination of one $\mathrm{CO}$. Therefore, the $\mathrm{CO}_{2}$ elimination step will take place after the leaving of the labile $\mathrm{CO}$ ligand, which next (after the $\mathrm{CO}_{2}$ release) will coordinate to the ruthenium in complex 6 to recover the catalytic species 7 .

The two most kinetically demanding transition states of the catalytic cycle $A$ correspond to the $\mathrm{N}_{2}$ and the $\mathrm{CO}_{2}$ releases, competing to be the rate determining step (rds). In the case of the $\mathrm{N}_{2}$ release, there is an energy barrier of $33.5 \mathrm{kcal} / \mathrm{mol}$ even so, this step is in competition with the previous $\mathrm{N}_{2} \mathrm{O}$ insertion, with an energy barrier of $31.4 \mathrm{kcal} / \mathrm{mol}$, and thus, both transition states must be taken into account. ${ }^{28}$ However, the absolute rds corresponds to the last $\mathrm{CO}_{2}$ release with an energy barrier of $35.7 \mathrm{kcal} / \mathrm{mol}$. Even though experimentally by any reason it could be possible that the $\mathrm{CO}$ is not able to recoordinate from intermediate $\mathbf{1 1}$ equatorial, it is necessary to point out that kinetically by calculations we must describe the pessimistic scenario, calculating the energy cost from $\mathbf{1 2}$.

The isomer of the PNN hydride species 7, with the aromatized PNC pincer type complex 8 , can also catalyze the $\mathrm{CO}$ oxidation by $\mathrm{N}_{2} \mathrm{O}$, as shown in Figure 2 (cycle B in Scheme 2). Qualitatively the mechanisms proceed in the same way as cycle A, in Figure 1.

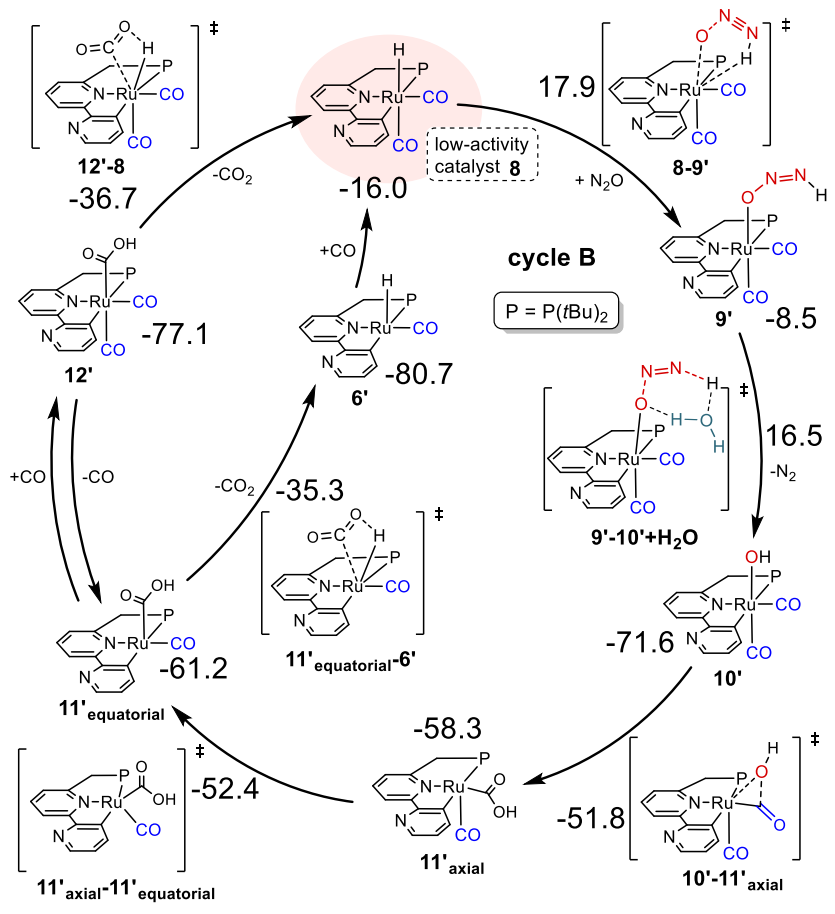

Figure 2. Computed mechanism for the $\mathrm{CO}$ oxidation by $\mathrm{N}_{2} \mathrm{O}$ homogeneously catalyzed by ruthenium hydride pincer $\mathbf{8}$ following cycle $\mathrm{B}$ (relative Gibbs energies in solution and referred to catalyst $\mathbf{6}+\mathrm{CO}+\mathrm{N}_{2} \mathrm{O}$ ). Energies are given in $\mathrm{kcal} / \mathrm{mol}$. All data shown were calculated at $\mathrm{T}=70{ }^{\circ} \mathrm{C}$, mimicking the experiments (see Figure S3 for further details).

The relative exoergonicity of $\mathbf{8}$ with respect to $7(1.5 \mathrm{kcal} / \mathrm{mol})$ explains in part the increase of the $\mathrm{N}_{2} \mathrm{O}$ insertion Gibbs energy barrier by $2.5 \mathrm{kcal} / \mathrm{mol}$. Contrarily to what happens for 7 , the $\mathrm{N}_{2}$ release is $1.4 \mathrm{kcal} / \mathrm{mol}$ kinetically more facile than the $\mathrm{N}_{2} \mathrm{O}$ insertion. Until the $\mathrm{N}_{2} \mathrm{O}$ insertion step, the comparison between 
PNC in cycle B and PNN pincer complex in cycle A (cycles A and $B$ present barriers of 33.5 and $33.9 \mathrm{kcal} / \mathrm{mol}$, respectively) suggests that cycle $\mathrm{B}$ is only $0.4 \mathrm{kcal} / \mathrm{mol}$ more kinetically demanding, but following with the rest of cycle $\mathrm{B}$, we realize that the upper energy barrier of cycle $\mathrm{B}$, i.e. $\mathrm{CO}_{2}$ release, requires to overcome a barrier of $41.8\left(\Delta \mathrm{G}^{\ddagger}\right.$ between $\mathbf{1 2}$ and $\mathbf{1 1}$ equatorial-6) or $40.4\left(\Delta \mathrm{G}^{\ddagger}\right.$ between 12 and 12-6, respectively) $\mathrm{kcal} / \mathrm{mol}$. The latter energy barrier is 4.7 $\mathrm{kcal} / \mathrm{mol}$ higher than for the PNN pincer type coordination (cycle A). Thus, it is also computationally confirmed, in agreement with experiments, that the PNC type coordination (cycle B) leads to a worse catalytic efficiency.

The two isomers $\mathbf{7}$ and $\mathbf{8}$ can be interconnected through the isomerization process involving the intermediates displayed in Figure 3a. We have fully characterized the whole reaction mechanism of the transformation from $\mathbf{7}$ to $\mathbf{8}$. First of all, the decoordination of the terminal pyridine of the PNN ligand takes place with an energy barrier of $27.2 \mathrm{kcal} / \mathrm{mol}$ forming a rather unstable unsaturated intermediate (13). Then, if there is a proper orientation of the pyridine ring, the $\mathrm{C}-\mathrm{H}$ in meta with respect the $\mathrm{N}$ atom is activated and the intermediate $\mathbf{1 4}$ is formed, overcoming an energy barrier of $10.3 \mathrm{kcal} / \mathrm{mol}$. The resulting intermediate $\mathbf{1 4}$ has $\mathrm{a} \mathrm{H}_{2}$ molecule bonded to the $\mathrm{Ru}$ atom. From this intermediate the system evolves to complex $\mathbf{8}$ by means of a hydrogen abstraction (inverse $\beta$-hydride elimination). As a result, we obtain species $\mathbf{8}$ overcoming an energy barrier of $10.0 \mathrm{kcal} / \mathrm{mol}$. As a whole, the global energy barrier is of $35.9 \mathrm{kcal} / \mathrm{mol}$ starting from 7 . The resulting complex $\mathbf{8}$ is more aromatic than $\mathbf{7}$ (vide infra) and it is more stable too, which makes difficult the reverse step to reconvert $\mathbf{8}$ into 7. Interestingly, the barrier that links $\mathbf{7}$ to $\mathbf{8}$ is only 0.2 $\mathrm{kcal} / \mathrm{mol}$ above the upper barrier that we found for the catalytic cycle A. The small energy difference concurs with the experimental observations that the two processes occur simultaneously, resulting in less efficient catalytic activity. Moreover, by thermodynamics, with the passage of time complex 7 will be converted into 8 , which presents a less efficient mechanism (cycle B) since the reaction barrier of the rds is higher in energy than in the case of cycle A. Therefore, the detailed understanding of the conversion mechanism will help us to find out new strategies to avoid it, and thereby improving the catalysis.

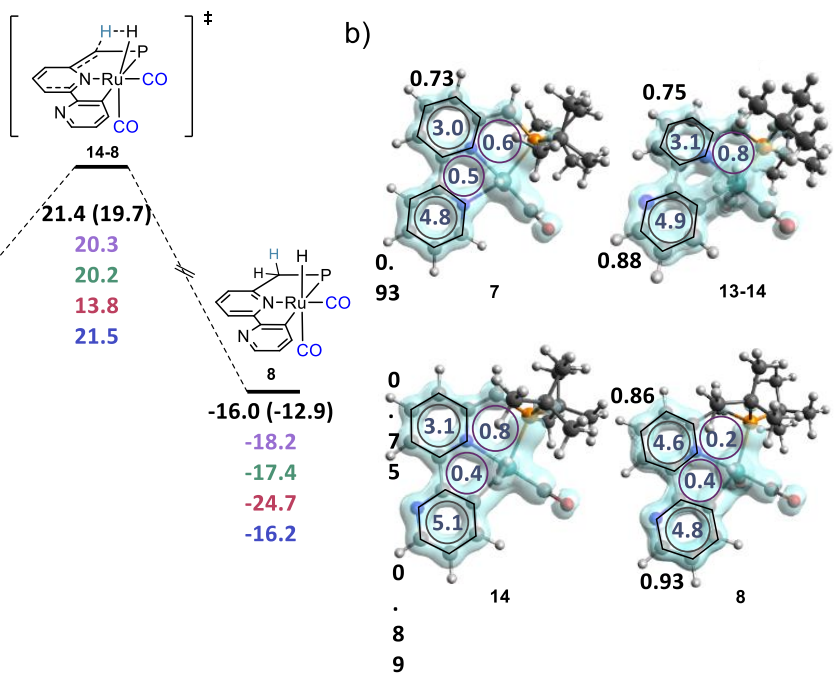

a)

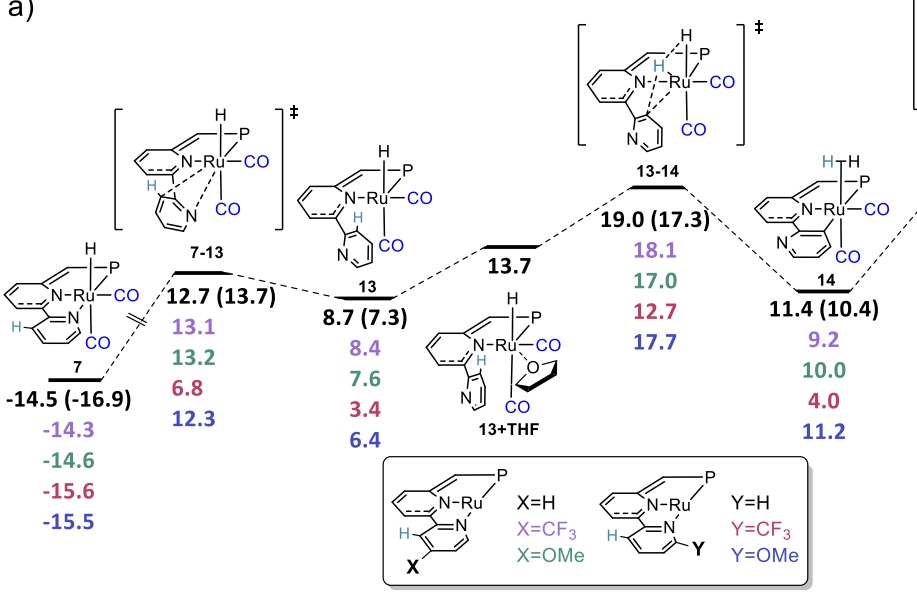

Figure 3. (a) Reaction mechanism of the interconversion between $\mathbf{7}$ and $\mathbf{8}$, relative Gibbs energies (in kcal/mol, referred to catalyst $6+\mathrm{CO}+\mathrm{N}_{2} \mathrm{O}$ ) using THF (toluene in parentheses) as solvent. In all cases and $\mathrm{P}=\mathrm{P} t \mathrm{Bu}_{2}$. As shown in the inset, the relative Gibbs energy values in purple, green, red, and blue correspond to the species with - $\mathrm{CF}_{3}$ and -OMe group in para with respect the $\mathrm{N}$ (X position) or the $\mathrm{C}$ $\mathrm{H}$ ( $\mathrm{Y}$ position). In all cases, when $\mathrm{X}=\mathrm{CF}_{3}$ or $\mathrm{OMe}, \mathrm{Y}=\mathrm{H}$ and viceversa. (b) Aromaticity results: The blue surface is the global resonance $\left(\operatorname{EDDB}(\mathbf{r})_{\mathrm{G}}\right)$ of the whole system and grey numbers inside the rings represent the electron density of delocalized bonds (EDDB) index for the rings of the pincer ligand, the black numbers outside the hexagons correspond to the HOMA values for the 6-MRs.

Experimentally, Milstein and coworkers found out that the catalytic activities increase when they change the solvent from toluene to tetrahydrofuran (THF). We tested the possible formation of a THFRu complex adduct (13+THF), that will block the formation of 8 . We found that the 7 THF adduct is unstable with respect to dissociation to $7+$ THF by $13.7 \mathrm{kcal} / \mathrm{mol}$, and, therefore, this intermediate is not preventing the isomerization. In addition, we computed the catalytic activity of 7 in toluene at $100^{\circ} \mathrm{C}$, reproducing the experimental conditions (see Tables S2 and S4). And the barriers for $\mathrm{N}_{2}$ and $\mathrm{CO}_{2}$ release are 35.9 and $34.9 \mathrm{kcal} / \mathrm{mol}$, respectively. Compared to the values obtained for THF, the $\mathrm{N}_{2}$ release barrier has increased, becoming higher than the original $\beta$ hydride elimination rds by $0.2 \mathrm{kcal} / \mathrm{mol}$, while for the $\mathrm{CO}_{2}$ release it has decreased by $0.8 \mathrm{kcal} / \mathrm{mol}$. The rds in toluene corresponds to the $\mathrm{N}_{2}$ release, whereas in THF the rds is the $\mathrm{CO}_{2}$ release. The former requires $0.2 \mathrm{kcal} / \mathrm{mol}$ more than the latter, in agreement with experimental observations.

To further characterize the electronic structure of compounds 7 and 8 and understand their different reactivity, we have analyzed the aromaticity, geometries, Mayer bond orders (MBO), atomic charges, and effective oxidation states (EOS) of these two species 
(Figures $3 \mathrm{~b}$ and 4 and Tables S5-S8). We employed several aromaticity indices based on magnetic, geometric, and electronic criteria, to determine the aromaticity of the two 6-membered rings (-MRs) of the pincer ligand and the two 5-MRs formed between this ligand and the metal.
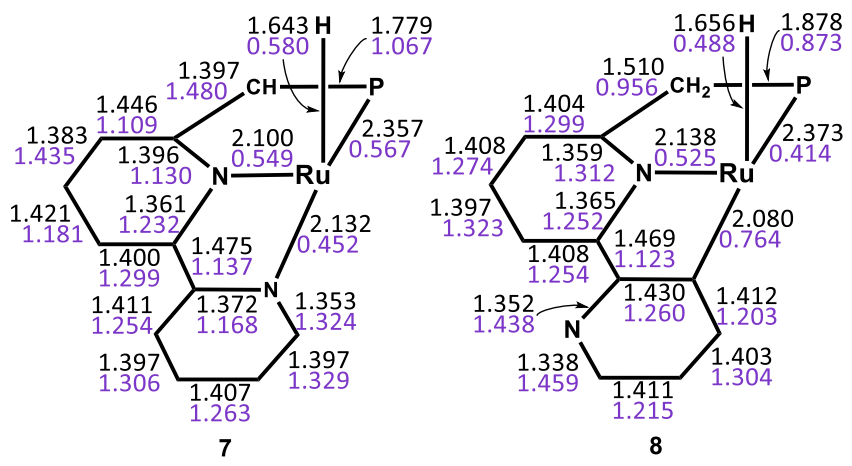

Figure 4. Bond distances in $\AA$ (black) and MBOs in e (violet) of the pincer and the hydride ligand in complexes $\mathbf{7}$ and $\mathbf{8}$.

For the analysis of aromaticity results, we took as a reference isolated pyridine and consistently we have computed all the indices for this system. In the particular case of EDDB, isolated pyridine (our reference as aromatic compound) has a value of 5.5 delocalized electrons. For all the intermediates of the isomerization process, the aromaticity indices employed point in the same direction, indicating that the 5-MRs are non-aromatic while the 6MR present some aromatic character (see Figure $3 b$ ). Intermediate 8 is the most aromatic compound, with HOMA values close to 0.90 in both 6-MR. The central 6-MR of the PNN in intermediates 7, 1314, and 14 (and the same for 13, not shown in Figure 3b, but depicted in Figure S13) has weak aromatic character, with HOMA values around 0.75 and a difference of more than two delocalized electrons (with respect to pyridine) according to EDDB results. On the other hand, the external 6-MR has aromatic character in all intermediates (HOMA close to 0.90 and EDDB close to 5 electrons). Finally, in the case of intermediate 8 the central 6-MR has gained aromatic character, making both 6-MRs equally aromatic. One can also notice that part of the $\sim 1.5$ electrons gained by the central ring come from the $\mathrm{C}=\mathrm{C}$ bond in the phosphine side, which changes its character from double (in $7,13,13-14$, and 14) to single (in $\mathbf{8}$ ) bond. The results obtained with other electronic indices (see Table S9) lead to the same conclusions.

In terms of structure, the main differences between $\mathbf{7}$ and $\mathbf{8}$ are in the central pyridine and the bridging $\mathrm{C}$ of the pincer. For the bridging $\mathrm{C}-\mathrm{C}$ bond the distance increase by $0.113 \AA$ from 7 to 8 and the $\mathrm{MBO}$ decreases by 0.524 electrons indicating that the character of the bond changes from double to single. ${ }^{29}$ On the contrary, some bonds of the central ring change the character from single (in 7) to aromatic (in $\mathbf{8}$ ), in good agreement with the aromaticity analyses.

Table 1. Gibbs energy barriers of the main elementary steps for the $\mathrm{CO}$ oxidation by $\mathrm{N}_{2} \mathrm{O}$ catalyzed by ruthenium hydride complexes (shown in Figure S5 of the SI). Energies in kcal/mol for the most relevant steps of the reaction shown in Figure S6 of the SI. All data shown was calculated at $\mathrm{T}=70^{\circ} \mathrm{C}$, with $\mathrm{THF}$ as solvent.

\begin{tabular}{|c|c|c|c|c|c|c|c|c|c|c|c|}
\hline catalyst & $7-9$ & $7-10+\mathrm{H}_{2} \mathrm{O}$ & $9-10+\mathrm{H}_{2} \mathrm{O}$ & $11_{\text {equatorial-6 }}$ & $12-6^{a}$ & $12-7$ & $7-13$ & $7-14$ & 13-14 & $7-8^{b}$ & 14-8 \\
\hline 5 & 31.4 & 33.5 & 22.7 & 26.6 & 35.7 & 42.5 & 27.2 & 33.5 & 10.3 & 35.9 & 10.0 \\
\hline 4 & 30.7 & 29.6 & 22.2 & 30.0 & 45.3 & 42.3 & 26.8 & 34.4 & 12.7 & 36.3 & 11.3 \\
\hline $\mathbf{P}\left(\mathrm{CH}_{3}\right)_{2}$ & 31.0 & 29.6 & 21.5 & 27.8 & 43.7 & 41.3 & 26.3 & 35.6 & 13.4 & 38.0 & 10.4 \\
\hline $\mathbf{P}\left(\mathrm{CF}_{3}\right)_{2}$ & 34.3 & 33.8 & 20.5 & 30.0 & 43.2 & 41.8 & 31.1 & 36.1 & 11.2 & 45.3 & 16.9 \\
\hline external $o-\mathrm{CF}_{3}$ & 32.0 & 32.9 & 20.9 & 26.6 & 34.5 & 41.3 & 22.4 & 28.3 & 9.3 & 29.4 & 9.8 \\
\hline external $p-\mathrm{CF}_{3}$ & 32.1 & 33.7 & 23.0 & 27.0 & 35.7 & 43.2 & 27.4 & 32.4 & 9.7 & 34.7 & 11.1 \\
\hline central $p-\mathrm{CF}_{3}$ & 32.9 & 33.7 & 22.2 & 26.8 & 34.7 & 42.0 & 26.9 & 33.6 & 10.1 & 37.2 & 11.6 \\
\hline$p-\mathrm{CF}_{3}$ & 32.5 & 33.8 & 22.8 & 26.4 & 34.4 & 42.5 & 26.8 & 32.3 & 9.8 & 35.9 & 12.7 \\
\hline external $o$-OMe & 31.0 & 33.3 & 24.1 & 26.3 & 35.9 & 42.1 & 27.8 & 33.2 & 11.3 & 37.0 & 10.3 \\
\hline external $p$-OMe & 31.5 & 33.3 & 23.0 & 26.6 & 35.6 & 42.8 & 27.8 & 31.6 & 9.4 & 34.8 & 10.2 \\
\hline central $p$-OMe & 31.4 & 33.4 & 22.8 & 26.4 & 35.8 & 43.2 & 26.2 & 32.7 & 10.1 & 34.6 & 9.7 \\
\hline$p$-OMe & 31.0 & 33.2 & 23.1 & 26.4 & 35.7 & 43.1 & 26.5 & 30.8 & 9.1 & 33.4 & 9.7 \\
\hline 2 & 33.3 & 33.7 & 21.7 & 26.2 & 32.7 & 41.5 & - & - & - & - & - \\
\hline 3 & 32.0 & 33.8 & 22.7 & 29.7 & 35.7 & 40.1 & - & - & - & - & - \\
\hline 15 & 43.3 & 44.0 & 17.4 & 32.1 & 31.6 & 44.6 & - & - & - & - & - \\
\hline 16 & 32.2 & 33.3 & 22.6 & 29.2 & 35.7 & 40.3 & - & - & - & - & - \\
\hline
\end{tabular}

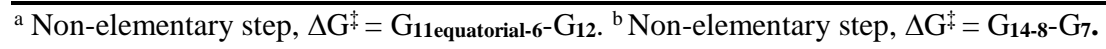

Our goal of improving the catalytic activity is focused in preventing the isomerization reaction of Figure 3. Specially, we tried to avoid the $\mathrm{C}-\mathrm{H}$ activation step of this last mechanism. Further, the main steps of cycle A were also calculated for the sake of comparison between the upper barrier of the catalytic cycle with respect to the barrier of the conversion from $\mathbf{7}$ to $\mathbf{8}$. Therefore, by means of predictive catalysis, we have proposed and tested different PNN ligands. On the one hand, we have evaluated the substituent effect with an electron-withdrawing group (EWG,- $\left.\mathrm{CF}_{3}\right)$ and an electrondonating group (EDG,-OMe) in para positions with respect to the $\mathrm{N}$ atom (external $\boldsymbol{p}$-X or external $\boldsymbol{o}-\mathbf{X})$ and $\mathrm{C}-\mathrm{H}$ bond $(\boldsymbol{p}-\mathbf{X})$, activated in the isomerization process, in the lateral ring of the PNN ligand (groups $\mathrm{X}$ and $\mathrm{Y}$ in Figure 3a, respectively). We also anayzed the effect of having the same EDG or EWG in para position with respect the $\mathrm{N}$ in the central ring (central $\boldsymbol{p}$-X). Unfortunately, in terms of energy no significant differences were 
observed, apart from a small decrease of about $1 \mathrm{kcal} / \mathrm{mol}$ in the barrier of the $\mathrm{CO}_{2}$ release in some cases like the external $\boldsymbol{o}-\mathbf{C F}_{3}$, central $\boldsymbol{p}-\mathbf{C F}_{\mathbf{3}}$ and $\boldsymbol{p}-\mathbf{C F}_{3}$. In the case of central $\boldsymbol{p}-\mathbf{C F}_{\mathbf{3}}$, there is also an increase of more than $1 \mathrm{kcal} / \mathrm{mol}$ in the barrier of the isomerization process (barrier 7-8, Table 1). This goes in the same direction as our aim to prevent catalyst isomerization. On the other hand, we tested the effect of changing the phosphine ligands. Going from $\mathrm{P}(t \mathrm{Bu})_{2}$ (complex 5) to less bulky phosphines $\mathrm{P}(i \mathrm{Pr})_{2}$ (complex 4), $\mathrm{P}\left(\mathrm{CH}_{3}\right)_{2}$ or $\mathrm{P}\left(\mathrm{CF}_{3}\right)_{2}$, we have seen that the 12-7 transition state becomes more kinetically facile than the 12-6 one (see Table S4) the corresponding energy barriers being 42.3, 41.3, and $41.8 \mathrm{kcal} / \mathrm{mol}$, respectively. Anyway, in all the latter three cases, the rds is higher in energy by at least $5.7 \mathrm{kcal} / \mathrm{mol}$ than for the complex with $\mathrm{P}(t \mathrm{Bu})_{2}$. In the case of the $\mathrm{N}_{2} \mathrm{O}$ reduction catalysis, the substitution of the $\mathrm{P}(t \mathrm{Bu})_{2}$ phosphine moiety by $\mathrm{P}(i \mathrm{Pr})_{2}$ or $\mathrm{P}\left(\mathrm{CH}_{3}\right)_{2}$ improves by 3.9 and $3.8 \mathrm{kcal} / \mathrm{mol}$, respectively, the kinetics of the first step (water assisted step 7-10+ $\mathbf{H}_{2} \mathbf{O}$ ). The reduction of the sterical hindrance on the metal center clearly facilitates the process. Thus, sterically it is possible to somewhat make up the kinetic cost. In the case of $\mathrm{P}\left(\mathrm{CF}_{3}\right)_{2}$ the energy barrier for the $\mathbf{7 - 1 0 +} \mathbf{H}_{\mathbf{2}} \mathrm{O}$ step is slightly larger by $0.3 \mathrm{kcal} / \mathrm{mol}$ than in the case of $\mathrm{P}(t \mathrm{Bu})_{2}$. However, with all the new tested phosphines, the barrier of the last $\mathrm{CO}_{2}$ release (either 12-6 or 12-7) increases by at least $7.5 \mathrm{kcal} / \mathrm{mol}$. Therefore, the change of $\mathrm{P}(t \mathrm{Bu})_{2}$ by the less bulky $\mathrm{P}(\mathrm{iPr})_{2}, \mathrm{P}\left(\mathrm{CH}_{3}\right)_{2}$ or $\mathrm{P}\left(\mathrm{CF}_{3}\right)_{2}$ ligands does not lead to an improvement of the catalyst.

Alternatively, we have also evaluated the effect of other pincer ligands (2, 3, and with another PNP ligand, 15, see Scheme 3) previously tested experimentally by Milstein and coworkers. ${ }^{23} \mathrm{We}$ selected these catalysts because even though the experimental TONs obtained were lower than for $\mathbf{5}$, their structures do not allow the isomerization of the pincer ligand (in the case of $\mathbf{3}$, the lateral ring is a pyrimidine, thus the isomerization of the ligand gives the same compound). We found that with $\mathbf{2}$ and $\mathbf{3}$ there is no substantial difference in the energy barriers of the first two steps. However, in comparison to the reference $\mathbf{5}$, with $\mathbf{1 5}$ the $\mathrm{N}_{2}$ release process is kinetically disfavored by $10.5 \mathrm{kcal} / \mathrm{mol}$. This is in good agreement with the fact that experimentally they just observed traces of product using 15. Regarding the $\mathrm{CO}_{2}$ release step, only catalyst 2 presented a smaller barrier (by $3.0 \mathrm{kcal} / \mathrm{mol}$ as compared to catalyst 5), which is reasonable taking into account that TONs reported in toluene and $100{ }^{\circ} \mathrm{C}$ for catalysts 2 and 5 were 62 and 24, respectively. Finally, we proposed a new PNN ligand with a phenanthroline moiety (16) to constrain the free rotation of the lateral pyridine ring. In this case, we found similar barriers than for 5 in cycle A. Actually the $\mathrm{N}_{2}$ release is favored by $0.2 \mathrm{kcal} / \mathrm{mol}$, whereas the $\mathrm{CO}_{2}$ release proceeds with the same barrier, thus the rds requires again $35.7 \mathrm{kcal} / \mathrm{mol}$ ), with the advantage that the isomerization cannot take place. Consequently, we propose that $\mathbf{1 6}$ will be a better candidate for the catalysis.

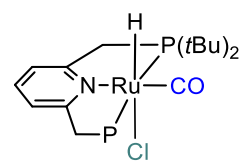

15

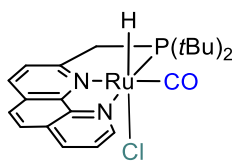

16
Scheme 3. Ruthenium hydride complexes $\mathbf{1 5}$ and $\mathbf{1 6 .}$

By comparing the geometries of the transition states equivalent to 7-9 with ligands $\mathbf{2}, \mathbf{5}, \mathbf{1 5}$, and $\mathbf{1 6}$, one can notice that there is a big difference between complexes having a PNN $(\mathbf{2}, \mathbf{5}, \mathbf{1 6})$ or PNP (15) ligand (Figure 5a). In the last case, the $\mathrm{N}_{2} \mathrm{O}$ has to coordinate perpendicular to the equatorial plane due to the sterical hindrance of the $t \mathrm{Bu}$ groups of the phosphines, which explains the destabilization of this transition state. On the other hand, in case of the PNN complexes the $\mathrm{N}_{2} \mathrm{O}$ is bent to the site of the lateral ring, minimizing the steric repulsion. Between them, these three complexes look pretty similar and it might seem that as long as we do not block the coordination site of the $\mathrm{N}_{2} \mathrm{O}$ (by using bulky ligands) we will not increase the energy. With the transition state 11 equatorial-6, the main difference comes from the possible orientation and the interaction between the $\mathrm{O}$ of the $\mathrm{CO}_{2}$ with other ligands. This is the case of complex $\mathbf{2}$, in which the structure of the transition state $\mathbf{1 1}$ equatorial-6 is stabilized by the formation of an intramolecular hydrogen bond between the $\mathrm{O}$ and the $\mathrm{N}-\mathrm{H}$ (see 2 in Figure 5b).
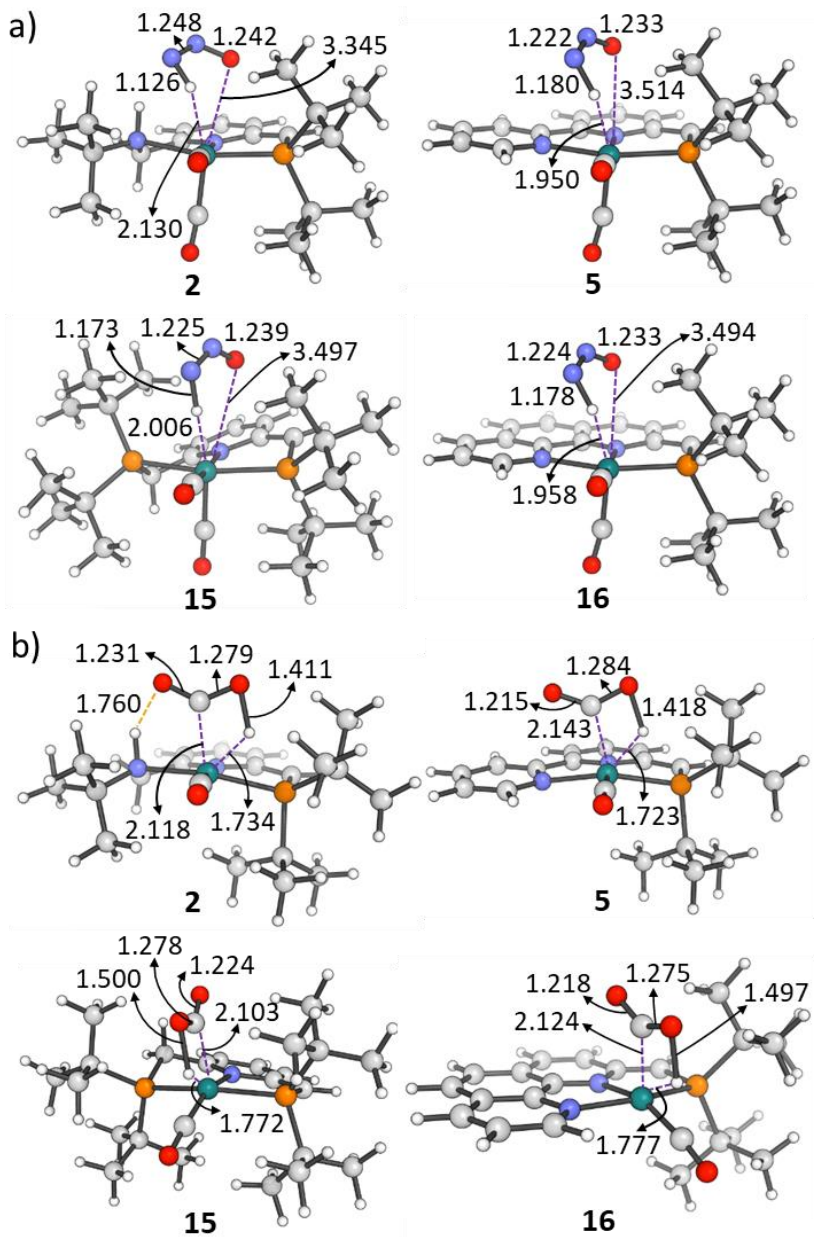
Figure 5. Transition state corresponding to steps (a) 7-9 and (b) 11 equatorial-6 for different catalysts (selected bond distances in $\AA$ ).

\section{CONCLUSIONS}

Milstein and coworkers ${ }^{23}$ developed a PNN pincer ruthenium catalyst for the homogeneous fixation of nitrous oxide $\left(\mathrm{N}_{2} \mathrm{O}\right)$, an ozone-depleting substance and the third most important greenhouse gas, to generate dinitrogen and $\mathrm{CO}_{2}$ as resultant products. In this work, we have performed DFT calculations to unravel the reaction mechanism. We have also analyzed different solutions to block the potential deactivation channel of the best catalyst to improve its efficiency. The characterization of the mechanism described two highly kinetically demanding steps that consist of the $\mathrm{N}_{2}$ and $\mathrm{CO}_{2}$ releases, being the latter the rds in THF. On the other hand, the PNN pincer ligand can isomerize to a PNC arrangement by a $180^{\circ}$ rotation of the lateral pyridine ring, with a $\mathrm{Ru}-\mathrm{N}$ bond cleavage. This isomerization reduces the catalytic performance of the catalyst. In order to address this drawback, we focused our efforts in unveiling the full mechanism of this PNC $\mathrm{Ru}$ based conformation, as well as the conversion from the PNN to the PNC pincer type coordination. From in silico predictions, we found that a phenanthroline moiety in the PNN ligand would block completely this isomerization maintaining almost identical the energy barriers of the rds of the catalytic cycle (cycle A) despite the increased rigidity of the pincer ligand.

\section{- COMPUTATIONAL DETAILS}

All DFT static calculations were performed with the Gaussian 16 set of programs, ${ }^{30}$ using the BP86 functional of Becke and Perdew, ${ }^{31,32,33}$ together with the Grimme D3BJ correction term to the electronic energy. ${ }^{34}$ The electronic configuration of the molecular systems for main-group atoms was described with the double- $\zeta$ basis set of Ahlrichs and coworkers (standard split valence basis set with a polarization function, SVP keyword in Gaussian), ${ }^{35}$ whereas for ruthenium the small-core quasirelativistic Stuttgart/Dresden effective core potential, with an associated valence basis set (standard SDD keywords in Gaussian16), was employed. ${ }^{36,37,38}$ The geometry optimizations were performed without symmetry constraints, and analytical frequency calculations were carried out for the characterization of the located stationary points. These frequencies were used to calculate unscaled zero-point energies (ZPEs) as well as thermal corrections and entropy effects at $343.15 \mathrm{~K}$. Energies were obtained by single-point calculations on the optimized geometries with the M06-L functional ${ }^{39}$ and the cc-pVTZ basis set, ${ }^{40}$ and estimating solvent effects with the universal solvation model SMD of Cramer and Truhlar, ${ }^{41}$ using THF as solvent. The reported Gibbs energies in this work include energies obtained at the M06-L/cc-pVTZ sdd level of theory corrected with zero-point energies, thermal corrections, and entropy effects evaluated at $343.15 \mathrm{~K}$ with the BP86-D3BJ/SVP sdd method.
In addition, we have evaluated the Mayer bond orders, ${ }^{42}$ 3D-space charges, effective orbitals (eff-Os), and effective oxidation states. The three later analyses, have been computed at the M06-L/cc$\mathrm{pVTZ}$ sdd//BP86-D3BJ/SVP sdd level of theory using the topological fuzzy Voronoi cells (TFVC) 3D-space partitioning method implemented within the APOST-3D program. ${ }^{43,44}$ The atomic grid used for the numerical integrations was $70 \times 434$.

The changes in local aromaticity have been quantified using electronic and structural probes of local aromaticity. ${ }^{45}$ As electronic indices, we employed EDDB, MCI, Iring, and PDI, at the M06-L/cc-pVTZ sdd//BP86-D3BJ/SVP sdd level of theory. The multicenter indices $\mathrm{I}_{\mathrm{rin} g}$, MCI, and PDI measure the electron delocalization between different centers (just taking into account the atoms in para positions in the case of PDI) therefore, can be used to quantify the delocalization aspect of aromaticity. ${ }^{46}$ In the case of EDDB, the method is based on the representation of the 1electron density using the n-center bond orbitals, and it allows us to get visual (qualitative) and also quantitative results. ${ }^{47}$ Finally, as a structural measure of aromaticity, the harmonic oscillator model of aromaticity (HOMA) index, defined by Kruszewski and Krygowski, was used..$^{48}$ In this case, values close to 1 are indicative of aromatic structures, while values close to 0 indicate nonaromaticity. In this case the computational level was BP86D3BJ/SVP sdd. The software used for the computation of all the aromaticity indices are Gaussian 16 for obtaining the wavefunction files used in AIMAll together with ESI-3D packages for MCI, Iring, PDI, and HOMA; and NBO 6.0 software together with the in-house code available at http://www.eddb.pl/runeddb/ for the EDDB analysis. ${ }^{49,50,51,52}$

\section{Supporting Information}

Cartesian coordinates of all studied compounds are collected in the xyz file. The extended results including: isomer benchmark, complete reaction profiles, EOS, aromaticity analysis, energies and lowest frequency in the SI pdf file. This material is available free of charge via the Internet at http://pubs.acs.org.

\section{AUTHOR INFORMATION}

\section{Corresponding Author}

*albert.poater@udg.edu,miquel.sola@udg.edu

\section{ORCID}

Sílvia Escayola: 0000-0002-1159-7397

Miquel Solà: 0000-0002-1917-7450

Albert Poater: 0000-0002-8997-2599

\section{ACKNOWLEDGMENT}

S.E. thanks Universitat de Girona and Donostia International Physics Center (DIPC) for an IFUdG2019 PhD fellowship. A.P. is a Serra Húnter Fellow. A.P. and M.S. thank the Ministerio de Economía y Competitividad (MINECO) of Spain for projects 
PGC2018-097722-B-I00 and CTQ2017-85341-P and the Generalitat de Catalunya for project 2017SGR39 and the ICREA Academia prize 2019 awarded to A.P. We thank Prof. David Milstein for helpful discussion.

(1) Portmann, R. W.; Daniel, J. S.; Ravishankara, A. R. Research Stratospheric Ozone Depletion due to Nitrous Oxide: Influences of other Gases. Phil. Trans. R. Soc. B 2012, 367, 1256-1264.

(2) Johnston, H. S. Reduction of Stratospheric Ozone by Nitrogen Oxide Catalysts from supersonic Transport Exhaust. Science 1971, 173, 517-522. 1880.

(3) Freedman, B.; Frost, R. Gale Encyclopedia of Science 1995, 1875-

(4) Rodhe, H. A Comparison of the Contribution of Various Greenhouse Gases to the Greenhouse Effect. Science 1990, 248, 12171219.

(5) Inventory of U.S. Greenhouse Gas Emissions and Sinks: 19902017 (published 2019), developed by the U.S. Government to meet U.S commitments under the United Nations Framework Convention on Climate Change (UNFCCC)

(6) Ravishankara, A. R.; Daniel, J. S.; Portmann, R. W. Nitrous Oxide $\left(\mathrm{N}_{2} \mathrm{O}\right)$ : The Dominant Ozone-Depleting Substance Emitted in the 21st Century. Science 2009, 326, 123-125.

(7) Hsu, J.; Prather, M. J. Global Long-Lived Chemical Modes Excited in a 3-D Chemistry Transport Model: Stratospheric $\mathrm{N}_{2} \mathrm{O}, \mathrm{NO}_{\mathrm{y}}, \mathrm{O}_{3}$ and $\mathrm{CH}_{4}$ Chemistry. Geophys. Res. Lett. 2010, 37, L07805.

(8) Montzka, S. A.; Dlugokencky, E. J.; Butler, J. H. Non- $\mathrm{CO}_{2}$ Greenhouse Gases and Climate Change. Nature 2011, 476, 43-50.

(9) (a) Konsolakis, M. Recent Advances on Nitrous Oxide $\left(\mathrm{N}_{2} \mathrm{O}\right)$ Decomposition over Non-Noble-Metal Oxide Catalysts: Catalytic Performance, Mechanistic Considerations, and Surface Chemistry Aspects. ACS Catal. 2015, 5, 6397-6421. (b) Severin, K. Synthetic Chemistry with Nitrous Oxide. Chem. Soc. Rev. 2015, 44, 6375-6386. (c) Parmon, V. N.; Panov, G. I.; Uriarte, A.; Noskov, A. S. Nitrous Oxide in Oxidation Chemistry and Catalysis: Application and Production. Catal. Today 2005, 100, 115-131. (d) Tolman, W. B. Binding and Activation of $\mathrm{N}_{2} \mathrm{O}$ at Transition-Metal Centers: Recent Mechanistic Insights. Angew. Chem., Int. Ed. 2010, 49, 1018-1024.

(10) López, J. C.; Quijano, G.; Souza, T. S. O.; Estrada, J. M.; Lebrero, R.; Muñoz, R. Biotechnologies for Greenhouse Gases $\left(\mathrm{CH}_{4}, \mathrm{~N}_{2} \mathrm{O}\right.$, and $\left.\mathrm{CO}_{2}\right)$ Abatement: State of the Art and Challenges. Appl. Microbiol. Biotechnol. 2013, 97, 2277-2303.

(11) Davidson, E. A.; Kanter, D. Inventories and Scenarios of Nitrous Oxide Emissions. Environ. Res. Lett. 2014, 9, 105012-105024.

(12) (a) Kaplan, A. W.; Bergman, R. G. Nitrous Oxide Mediated Oxygen Atom Insertion into a Ruthenium-Hydride Bond. Synthesis and Reactivity of the Monomeric Hydroxoruthenium Complex (DMPE) $)_{2} \mathrm{Ru}(\mathrm{H})(\mathrm{OH})$. Organometallics 1997, 16, 1106-1108. (b) Lee, J.H.; Pink, M.; Tomaszewski, J.; Fan, H.; Caulton, K. G. Facile Hydrogenation of $\mathrm{N}_{2} \mathrm{O}$ by an Operationally Unsaturated Osmium Polyhydride. J. Am. Chem. Soc. 2007, 129, 8706-8707. (c) Doyle, L. E.; Piers, W. E.; Borau-Garcia, J. Ligand Cooperation in the Formal Hydrogenation of $\mathrm{N}_{2} \mathrm{O}$ Using a $\mathrm{PC}_{\mathrm{sp} 2} \mathrm{P}$ Iridium Pincer Complex. $J$. Am. Chem. Soc. 2015, 137, 2187-2190. (d) Gianetti, T. L.; Annen, S. P.; Santiso-Quinones, G.; Reiher, M.; Driess, M.; Grützmacher, H. Nitrous Oxide as a Hydrogen Acceptor for the Dehydrogenative Coupling of Alcohols. Angew. Chem., Int. Ed. 2016, 55, 1854-1858. (e) Gianetti, T. L.; Rodríguez-Lugo, R. E.; Harmer, J. F.; Trincado, M.; Vogt, M.; SantisoQuinones, G.; Grützmacher, H. Zero-Valent Amino-Olefin Cobalt Complexes as Catalysts for Oxygen Atom Transfer Reactions from Nitrous Oxide. Angew. Chem., Int. Ed. 2016, 55, 15323-15328.

(13) Zeng, R.; Feller, M.; Ben-David, Y.; Milstein, D. Hydrogenation and Hydrosilylation of Nitrous Oxide Homogeneously Catalyzed by a Metal Complex. J. Am. Chem. Soc. 2017, 139, 5720-5723.

\section{REFERENCES}

(14) (a) Benton, A. F.; Thacker, C. M. The Kinetics of Reaction between Nitrous Oxide and Hydrogen at a Silver Surface. J. Am. Chem. Soc. 1934, 56, 1300-1304. (b) Dixon, J. K.; Vance, J. E. The Reaction between Nitrous Oxide and Hydrogen on Platinum. J. Am. Chem. Soc. 1935, 57, 818-821. (c) Miyamoto, A.; Baba, S.; Mori, M.; Murakami, Y. Ion-Solvent Molecule Interactions in the Gas Phase. The Potassium Ion and Benzene. $J$. Phys. Chem. 1981, 85, 3117-3122. (d) Delahay, G.; Mauvezin, M.; Guzmán-Vargas, A.; Coq, B. Effect of the Reductant Nature on the Catalytic Removal of $\mathrm{N}_{2} \mathrm{O}$ on Fe-Zeolite- $\beta$ Catalysts. Catal. Commun. 2002, 3, 385-389. (e) Nobukawa, T.; Yoshida, M.; Okumura, K.; Tomishige, K.; Kunimori, K. Effect of Reductants in $\mathrm{N}_{2} \mathrm{O}$ Reduction Over Fe-MFI Catalysts. J. Catal. 2005, 229, 374-388.

(15) Chakraborty, S.; Gellrich, U.; Diskin-Posner, Y.; Leitus, G.; Avram, L.; Milstein, D. Manganese-Catalyzed N-Formylation of Amines by Methanol Liberating $\mathrm{H}_{2}$ : A Catalytic and Mechanistic Study. Angew. Chem., Int. Ed. 2017, 56, 4229-4233.

(16) Chakraborty, S.; Kumar Das, U.; Ben-David, Y.; Milstein, D. Manganese Catalyzed $\alpha$-Olefination of Nitriles by Primary Alcohols. J. Am Chem. Soc. 2017, 139, 11710-11713.

(17) Zhang, J.; Balaraman, E.; Leitus, G.; Milstein, D. Electron-Rich PNP- and PNN-Type Ruthenium(II) Hydrido Borohydride Pincer Complexes. Synthesis, Structure, and Catalytic Dehydrogenation of Alcohols and Hydrogenation of Esters. Organometallics 2011, 30, 57165724.

(18) Zell, T.; Ben-David, Y.; Milstein, D. Highly Efficient, General Hydrogenation of Aldehydes Catalyzed by PNP Iron Pincer Complexes. Catal. Sci. Technol. 2015, 5, 822-826.

(19) Gunanathan, C.; Milstein, D. Metal-Ligand Cooperation by Aromatization-Dearomatization: A New Paradigm in Bond Activation and "Green" Catalysis. Acc. Chem. Res. 2011, 44, 588-602.

(20) Luque-Urrutia, J. A.; Solà, M.; Milstein, D.; Poater, A. Mechanism of the Manganese-Pincer Catalyzed Acceptorless Dehydrogenative Coupling of Nitriles and Alcohols. J. Am. Chem. Soc. 2019, 141, 2398-2403.

(21) (a) Kuriyama, S.; Arashiba, K.; Nakajima, K.; Tanaka, H. Kamaru, N.; Yoshizawa, K.; Nishibayashi, Y. Catalytic Reduction of Dinitrogen to Ammonia by Use of Molybdenum-Nitride Complexes Bearing a Tridentate Triphosphine as Catalysts. J. Am. Chem. Soc. 2014, 136, 9719-9731. (b) Chang, Y.; Nakajima, Y.; Tanaka, H.; Yoshizawa, K. Facile N-H Bond Cleavage of Ammonia by an Iridium Complex Bearing a Noninnocent PNP-Pincer Type Phosphaalkene Ligand. J. Am. Chem. Soc. 2013, 135, 11791-11794. (c) Fillman, K. L.; Bielinski, E. A.; Schmeier, T. J.; Nesvet, J. C.; Woodruff, T. M.; Pan, C. J.; Takase, M. K.; Hazari, N.; Neidig, M. L. Flexible Binding of PNP Pincer Ligands to Monomeric Iron Complexes. Inorg. Chem. 2014, 53, 6066-6072. (d) Mellone, I.; Gorgas, N.; Bertini, F.; Peruzzini M.; Kirchner, K.; Gonsalvi, L. Selective Formic Acid Dehydrogenation Catalyzed by Fe-PNP Pincer Complexes Based on the 2,6-Diaminopyridine Scaffold. Organometallics 2016, 35, 3344-3349. (e) Bailey, W. D.; Kaminsky, W.; Kemp, R. A.; Goldberg, K. I. Synthesis and Characterization of Anionic, Neutral, and Cationic PNP Pincer Pd ${ }^{\mathrm{II}}$ and $\mathrm{Pt}^{\mathrm{II}}$ Hydrides. Organometallics 2014, 33, 2503-2509. (f) Yang Z.; Xia, C.; Liu, D.; Liu, Y.; Sugiya, M.; Imamoto, T.; Zhang, W. P-Stereogenic PNP Pincer-Pd Catalyzed Intramolecular Hydroamination of Amino-1,3-dienes. Org. Biomol. Chem. 2015, 13, 2694-2702. (g) Cheng, C.; Kim, B. G.; Guironnet, D.; Brookhart, M.; Guan, C.; Wang, D. Y.; Krogh-Jespersen, K.; Goldman, A. S. Synthesis and Characterization of Carbazolide-Based Iridium PNP Pincer Complexes. Mechanistic and Computational Investigation of Alkene Hydrogenation: Evidence for an $\operatorname{Ir}(\mathrm{III}) / \mathrm{Ir}(\mathrm{V}) / \mathrm{Ir}(\mathrm{III})$ Catalytic Cycle. J. Am. Chem. Soc. 2014, 136, 6672-6683. (h) Alberico, E. Lennox, A. J. J.; Vogt, L. K.; Jiao, H.; Baumann, W.; Drexler, H.; Nielsen, M.; Spannenberg, A.; Checinski, M. P.; Junge, H.; Beller, M. Unravelling 
the Mechanism of Basic Aqueous Methanol Dehydrogenation Catalyzed by Ru-PNP Pincer Complexes. J. Am. Chem. Soc. 2016, 138, 14890-14904. (i) Nakajima, Y.; Okamoto, Y.; Chang, Y. Ozawa, F. Synthesis, Structures, and Reactivity of Ruthenium Complexes with PNP-pincer Type Phosphaalkene Ligands. Organometallics 2013, 32, 2918-2925. (j) Öztopcu, Ö.; Holzhacker, C.; Puchberger, M.; Weil, M.; Mereiter, K.; Veiros, L. F.; Kirchner, K. Synthesis and Characterization of Hydrido Carbonyl Molybdenum and Tungsten PNP Pincer Complexes. Organometallics 2013, 32, 3042-3052. (k) Moha, V.; Leitner, W.; Hölscher M. $\mathrm{H}_{3}$ Synthesis in the $\mathrm{N}_{2} / \mathrm{H}_{2}$ Reaction System using Cooperative Molecular Tungsten/Rhodium Catalysis in Ionic Hydrogenation: A DFT Study. Chem. Eur. J. 2016, 22, 2624-2628. (1) Arashiba, K.; Sasaki, K.; Kuriyama, S.; Miyake, Y.; Nakanishi, H.; Nishibayashi, Y. Synthesis and Protonation of Molybdenum- and Tungsten-Dinitrogen Complexes Bearing PNP-Type Pincer Ligands. Organometallics 2012, 31, 2035-2041. (m) Vogt, M.; Rivada-Wheelaghan, O.; Iron, M. A.; Leitus, G.; Diskin-Posner, Y.; Shimon, L. J. W.; Ben-David, Y.; Milstein, D. Anionic Nickel(II) Complexes with Doubly Deprotonated PNP Pincer-type Ligands and Their Reactivity Toward $\mathrm{CO}_{2}$. Organometallics 2013, 32, 300-308. (n) Masdemont, J.; Luque-Urrutia, J. A.; Gimferrer, M.; Milstein, D.; Poater, A. Mechanism of Coupling of Alcohols and Amines to Generate Aldimines and $\mathrm{H}_{2}$ by a Pincer Manganese Catalyst. ACS Catal. 2019, 9, 1662-1669.

(22) Gonçalves, T. P.; Huang, K.-W. Metal-Ligand Cooperative Reactivity in the (Pseudo)-Dearomatized $\mathrm{PN}_{\mathrm{x}}(\mathrm{P})$ Systems: The Influence of the Zwitterionic Form in Dearomatized Pincer Complexes. J. Am. Chem. Soc. 2017, 139, 13442-13449.

(23) Zeng, R.; Feller, M.; Diskin-Posner, Y.; Shimon, L. J. W.; BenDavid, Y.; Milstein, D. CO Oxidation by $\mathrm{N}_{2} \mathrm{O}$ Homogeneously Catalyzed by Ruthenium Hydride Pincer Complexes Indicating a New Mechanism. $J$. Am. Chem. Soc. 2018, 140, 7061-7064.

(24) (a) Luconi, L.; Demirci, U. B.; Peruzzini, M.; Giambastiani, G.; Rossin, A. Ammonia Borane and Hydrazine Bis(borane) Dehydrogenation Mediated by an Unsymmetrical (PNN) Ruthenium Pincer Hydride: MetalLigand Cooperation for Hydrogen Production. Sustain. Energy Fuels 2019, 3, 2583-2596. (b) Gusev, D. G. Revised Mechanisms of the Catalytic Alcohol Dehydrogenation and Ester Reduction with the Milstein PNN Complex of Ruthenium. Organometallics 2020, 39, 258-270.

(25) (a) Yu, H.; Jia, G.; Lin, Z. Theoretical Studies on O-Insertion Reactions of Nitrous Oxide with Ruthenium Hydride Complexes. Organometallics 2008, 27, 3825-3833. (b) Luque-Urrutia, J. A.; Poater, A. The Fundamental Noninnocent Role of Water for the Hydrogenation of Nitrous Oxide by PNP Pincer Ru-based Catalysts. Inorg. Chem. 2017, 56, 14383-14387. (c) Yao, L.; Li, Y.; Huang, L.; Guo, K.; Ren, G.; Wu, Z.; Lei, Q.; Fang, W.; Xie, H. A DFT Study on the Mechanisms of Hydrogenation and Hydrosilylation of Nitrous Oxide Catalyzed by a Ruthenium PNP Pincer Complex. Comput. Theor. Chem. 2018, 1128, 48-55. (d) Xie, H.-J.; Zhang, Y.-T.M.; Xiang, C.-Y.; Li, Y.; Fan, T.; Lei, Q.-F.; Fang, W.-J. NonInnocent PNN Ligand is Important for $\mathrm{CO}$ Oxidation by $\mathrm{N}_{2} \mathrm{O}$ Catalyzed by a (PNN)Ru-H Pincer Complex: Insights from DFT Calculations. Dalton Trans. 2018, 47, 15324-15330.

(26) Tang, S.; Von Wolff, N.; Diskin-Posner, Y.; Leitus, G.; BenDavid, Y.; Milstein, D. Pyridine-Based PCP-Ruthenium Complexes: Unusual Structures and Metal-Ligand Cooperation. J. Am. Chem. Soc. 2019, 141, 7554-7561.

(27) Rossi, A. R.; Hoffmann, R. Transition Metal Pentacoordination. Inorg. Chem. 1975, 14, 365-374.

(28) Kozuch, S.; Shaik, S. How to Conceptualize Catalytic Cycles? The Energetic Span Model. Acc. Chem. Res. 2011, 44, 101-110.

(29) (a) Magi Meconi, G.; Vummaleti, S. V. C.; Luque-Urrutia, J. A.; Belanzoni, P.; Nolan, S. P.; Jacobsen, H.; Cavallo, L.; Solà, M.; Poater, A. Mechanism of the Suzuki-Miyaura Cross-Coupling Reaction Mediated by [Pd(NHC)(allyl)Cl] Precatalysts. Organometallics 2017, 36, 2088-2095. (b) Azofra, L. M.; Poater, A. Diastereoselective Diazenyl Formation: the Key for Manganese-Catalysed Alcohol Conversion Into (E)-alkenes. Dalton Trans. 2019, 48, 14122-14127.

(30) Gaussian 16, Revision C.01, Frisch, M. J.; Trucks, G. W.; Schlegel, H. B.; Scuseria, G. E.; Robb, M. A.; Cheeseman, J. R.; Scalmani, G.; Barone, V.; Petersson, G. A.; Nakatsuji, H.; Li, X.; Caricato, M.;
Marenich, A. V.; Bloino, J.; Janesko, B. G.; Gomperts, R.; Mennucci, B.; Hratchian, H. P.; Ortiz, J. V.; Izmaylov, A. F.; Sonnenberg, J. L.; WilliamsYoung, D.; Ding, F.; Lipparini, F.; Egidi, F.; Goings, J.; Peng, B.; Petrone, A.; Henderson, T.; Ranasinghe, D.; Zakrzewski, V. G.; Gao, J.; Rega, N.; Zheng, G.; Liang, W.; Hada, M.; Ehara, M.; Toyota, K.; Fukuda, R.; Hasegawa, J.; Ishida, M.; Nakajima, T.; Honda, Y.; Kitao, O.; Nakai, H.; Vreven, T.; Throssell, K.; Montgomery, J. A., Jr.; Peralta, J. E.; Ogliaro, F.; Bearpark, M. J.; Heyd, J. J.; Brothers, E. N.; Kudin, K. N.; Staroverov, V. N.; Keith, T. A.; Kobayashi, R.; Normand, J.; Raghavachari, K.; Rendell, A. P.; Burant, J. C.; Iyengar, S. S.; Tomasi, J.; Cossi, M.; Millam, J. M.; Klene, M.; Adamo, C.; Cammi, R.; Ochterski, J. W.; Martin, R. L.; Morokuma, K.; Farkas, O.; Foresman, J. B.; Fox, D. J. Gaussian, Inc., Wallingford CT, 2016.

(31) Becke, A. Density-Functional Exchange-Energy Approximation with Correct Asymptotic Behaviour. Phys. Rev. A 1988, 38, 3098-3100.

(32) Perdew, J. P. Density-Functional Approximation for the Correlation Energy of the Inhomogeneous Electron Gas. Phys. Rev. B 1986, $33,8822-8824$.

(33) Perdew, J. P. Erratum: Density-functional Approximation for the Correlation Energy of the Inhomogeneous Electron Gas. Phys. Rev. B 1986, $34,7406-7406$.

(34) (a) Grimme, S.; Antony, J.; Ehrlich, S.; Krieg, H. A Consistent and Accurate $\mathrm{Ab}$ Initio Parametrization of Density Functional Dispersion Correction (DFT-D) for the 94 Elements H-Pu. J. Chem. Phys. 2010, 132, 154104. (b) Grimme, S.; Ehrlich, S.; Goerigk, L. Effect of the Damping Function in Dispersion Corrected Density Functional Theory. J. Comp. Chem. 2011, 32, 1456-1465.

(35) Schäfer, S.; Horn, H.; Ahlrichs, R. Fully Optimized Contracted Gaussian Basis Sets for Atoms Li to Kr. J. Chem. Phys. 1992, 97, 25712577.

(36) Haeusermann, U.; Dolg, M.; Stoll, H.; Preuss, H. Schwerdtfeger, P.; Pitzer, R. M. Accuracy of Energy-Adjusted Quasirelativistic Ab Initio Pseudopotentials. Mol. Phys. 1993, 78, 1211-1224.

(37) Küchle, W.; Dolg, M.; Stoll, H.; Preuss, H. Energy-Adjusted Pseudopotentials for the Actinides. Parameter Sets and Test Calculations for Thorium and Thorium Monoxide. J. Chem. Phys. 1994, 100, 75357542.

(38) Leininger, T.; Nicklass, A.; Stoll, H.; Dolg, M.; Schwerdtfeger, P. The Accuracy of the Pseudopotential Approximation. II. A Comparison of Various Core Sizes for Indium Pseudopotentials in Calculations for Spectroscopic Constants of InH, InF, and InCl. J. Chem. Phys. 1996, 105, 1052-1059.

(39) (a) Zhao, Y.; Truhlar D. G. The M06 Suite of Density Functionals for Main Group Thermochemistry, Thermochemical Kinetics, Noncovalent Interactions, Excited States, and Transition Elements: Two New Functionals and Systematic Testing of Four M06-Class Functionals and 12 Other Functionals. Theor. Chem. Acc. 2008, 120, 215-241. (b) Zhao, Y.; Truhlar, D. G. A New Local Density Functional for Main-Group Thermochemistry, Transition Metal Bonding, Thermochemical Kinetics, and Noncovalent Interactions. J. Chem. Phys. 2006, 125, 194101:1-18.

(40) Kendall, R. A.; Dunning Jr., T. H.; Harrison, R. J. Electron Affinities of the First-Row Atoms Revisited. Systematic Basis Sets and Wave Functions. J. Chem. Phys. 1992, 96, 6796-6806.

(41) Marenich, A. V.; Cramer, C. J.; Truhlar, D. G. Universal Solvation Model Based on Solute Electron Density and a Continuum Model of the Solvent Defined by the Bulk Dielectric Constant and Atomic Surface Tensions. J. Phys. Chem. B 2009, 113, 6378-6396.

(42) (a) Mayer, I. Charge, Bond Order and Valence in the AB Initio SCF Theory. Chem. Phys. Lett. 1983, 97, 270-274. (b) Mayer, I. Bond Order and Valence: Relations to Mulliken's Population Analysis. Int. J. Quantum Chem. 1984, 26, 151-154.

(43) Salvador, P.; Ramos-Cordoba, E. Communication: An Approximation to Bader's Topological Atom. J. Chem. Phys. 2013, 139, 071103.

(44) (a) Ramos-Cordoba, E.; Postils, V.; Salvador, P. Oxidation States from Wave Function Analysis. J. Chem. Theory Comput. 2015, 11, 1501-1508. (b) Postils, V.; Delgado-Alonso, C.; Luis, J. M.; Salvador, P. An Objective Alternative to IUPAC's Approach To Assign Oxidation 
States. Angew. Chem., Int. Ed. 2018, 57, 10525-10529. (c) Poater, J.; Gimferrer, M.; Poater, A. Covalent and Ionic Capacity of MOFs To Sorb Small Gas Molecules. Inorg. Chem. 2018, 57, 6981-6990. (d) Gimferrer, M.; Salvador, P.; Poater, A. Computational Monitoring of Oxidation States in Olefin Metathesis. Organometallics 2019, 38, 4585-4592. (e) Skara, G.; Gimferrer, M.; De Proft, F.; Salvador, P.; Pinter, B. Scrutinizing the Noninnocence of Quinone Ligands in Ruthenium Complexes: Insights from Structural, Electronic, Energy, and Effective Oxidation State Analyses. Inorg. Chem. 2016, 55, 2185-2199.

(45) (a) Poater, A.; Ribas, X.; Llobet, A.; Cavallo, L.; Solà, M. Complete Mechanism of $\sigma^{*}$ Intramolecular Aromatic Hydroxylation through $\mathrm{O}_{2}$ Activation by a Macrocyclic Dicopper(I) Complex. J. Am. Chem. Soc. 2008, 130, 17710-17717. (b) Poater, A.; Cavallo, L. Simple Ligand Modifications as Key to Play with the Stability of $\mathrm{Cu}(\mathrm{I}), \mathrm{Cu}(\mathrm{II})$ and of $\mathrm{Cu}(\mathrm{III})-$ Organometallic Complexes. Inorg. Chem. 2009, 48, 2340-2342.

(46) (a) Bultinck, P.; Ponec, R.; Van Damme, S. Multicenter Bond Indices as a New Measure of Aromaticity in Polycyclic Aromatic Hydrocarbons. J. Phys. Org. Chem. 2005, 18, 706-718. (b) Poater, J.; Fradera, X.; Duran, M.; Solà, M. The Delocalization Index as an Electronic Aromaticity Criterion: Application to a Series of Planar Polycyclic Aromatic Hydrocarbons. Chem. Eur. J. 2003, 9, 400-406. (c) Feixas, F.; Matito, E.; Poater, J.; Solà, M. Quantifying Aromaticity with Electron Delocalisation Measures. Chem. Soc. Rev.. 2015, 44, 6434-6451.

(47) (a) Szczepanik, D. W.; Zak, E. J.; Dyduch, K.; Mrozek, J. Electron Delocalization Index Based on Bond Order Orbitals. Chem. Phys. Lett. 2014, 593, 154-159. (b) Szczepanik, D. W.; Andrzejak, M.; Dyduch, K.; Zak, E. J.; Makowski, M.; Mazur, G.; Mrozek, J. A Uniform Approach to the Description of Multicenter Bonding. Phys. Chem. Chem. Phys. 2014, 16, 20514-20523. (c) Szczepanik, D. W. A New Perspective on Quantifying Electron Localization and Delocalization in Molecular Systems. Comput. Theor. Chem. 2016, 1080, 33-37. (d) Szczepanik, D. W. On the Three-Center Orbital Projection Formalism Within the Electron Density of Delocalized Bonds Method. Comput. Theor. Chem. 2017, 1100, 13-17. (e) Szczepanik, D. W.; Andrzejak, M.; Dominikowska, J.; Pawełek, B.; Krygowski, T. M.; Szatyłowic, H.; Solà, M. The electron density of delocalized bonds (EDDB) applied for quantifying aromaticity. Phys. Chem. Chem. Phys., 2017, 19, 28970-28981.

(48) Kruszewski, J.; Krygowski, T. M. Definition of Aromaticity Basing on the Harmonic Oscillator Model. Tetrahedron Lett. 1972, 13, 3839-3842.

(49) Keith, T. A. AIMAll (Version 14.11.23), TK Gristmill Software: Overland Park KS, USA 2014.

(50) Matito, E. ESI-3D; IQCC and DIPC: Donostia, Euskadi, Spain, 2015.

(51) Matito, E.; Salvador, P.; Duran, M.; Solà, M. Aromaticity Measures from Fuzzy-Atom Bond Orders (FBO). The Aromatic Fluctuation(FLU) and the para-Delocalization (PDI) Indexes. J. Phys. Chem. A 2006, 110, 5108-5113. (c) Matito, E.; Solà, M.; Salvador, P.; Duran, M. Electron Sharing Indexes at the Correlated Level. Application to Aromaticity Measures. Faraday Discuss. 2007, 135, 325-345.

(52) Glendening, E. D.; Badenhoop, J. K.; Reed, A. E.; Carpenter, J. E.; Bohmann, J. A.; Morales, C. M.; Landis, C. R.; Weinhold, F. NBO 6.0, Theoretical Chemistry Institute, University of Wisconsin: Madison, 2013. 


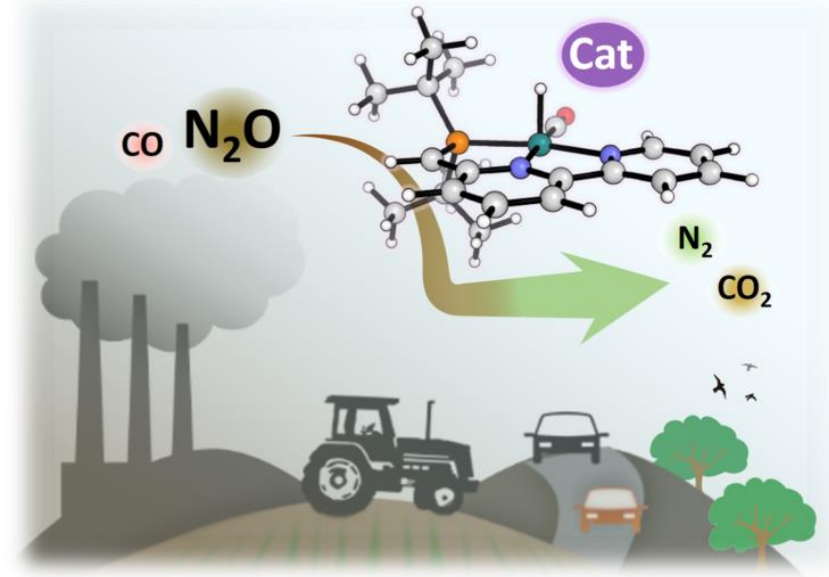

Better catalytic activity of a (PNN)Ru based catalyst for the reduction of $\mathrm{N}_{2} \mathrm{O}$ by $\mathrm{CO}$ from DFT calculations. 